\title{
Development of apractice guideline for dietary counselling of children with IgE-mediated food allergy
}

\section{Eisenblaetter, J}

http://hdl.handle.net/10026.1/15854

\subsection{7/s40629-020-00124-8}

Allergo Journal International

Springer Science and Business Media LLC

All content in PEARL is protected by copyright law. Author manuscripts are made available in accordance with publisher policies. Please cite only the published version using the details provided on the item record or document. In the absence of an open licence (e.g. Creative Commons), permissions for further reuse of content should be sought from the publisher or author. 


\section{Development of a practice guideline for dietary counselling of children with lgE-mediated food allergy}

Julia Eisenblaetter ${ }^{1,11}$, Selina Bürklin ${ }^{1}$, Ashley Gschwend ${ }^{1}$, Claudia Relats ${ }^{1}$, Caroline Roduit ${ }^{2,3,4}$, Karin Stalder ${ }^{5}$, Isabel Fischer ${ }^{4}$, Daniela Hofmann ${ }^{6}$, Gabrielle Schütt ${ }^{4}$, Regula Herzog ${ }^{7}$ Daniel Gianelli ${ }^{7}$, Monique Mura ${ }^{8}$, Petra Martel $^{9}$, Andrea Werder ${ }^{10}$, Lina Martin ${ }^{10}$, Mary Hickson $^{11}$, Isabel Skypala ${ }^{12}$, Anne Payne ${ }^{11}$

${ }^{1}$ Bern University of Applied Sciences, Division of Nutrition and Dietetics, Berne, Switzerland

${ }^{2}$ Children's Hospital St Gallen, St Gallen, Switzerland

${ }^{3}$ Christine Kuehne-Center for Allergy Research and Education (CK-CARE), Davos, Switzerland

${ }^{4}$ University Children's Hospital Zurich, Zurich, Switzerland

${ }^{5}$ aha! Swiss Allergy Centre, Berne, Switzerland

${ }^{6}$ University Hospital Inselspital Bern, Department of Pediatrics, Berne, Switzerland

${ }^{7}$ Hochgebirgsklinik Davos, Davos, Switzerland

${ }^{8}$ Aarau Cantonal Hospital, Department of Children and Adolescent Medicine, Aarau, Switzerland

${ }^{9}$ Praxis für Ernaehrungsberatung, Blumenfeld, Switzerland

${ }^{10}$ University Children's Hospital, Basel, Switzerland

${ }^{11}$ Institute of Health and Community, School of Health Professions, Plymouth University, Plymouth, UK

${ }^{12}$ Royal Brompton Hospital, London, UK

Corresponding author: Julia Eisenblaetter, julia.eisenblaetter@bfh.ch, tel: +41 31848 3771, ORCID: 0000-0002-

1786-6797 


\begin{abstract}
Purpose

The incidence of food allergy is increasing globally and whilst there is consensus that dietitians should be involved in its management, the roles that dietitians should fulfil differ between different guidelines and the description of tasks remains unclear. Currently, no Swiss guideline exists to assist dietitians in counselling children with food allergies. There is a need for recommendations that will guide dietitians through the counselling process. The aim of this project was to create a practice guideline for dietary counselling of children with food allergy.
\end{abstract}

\title{
Methods
}

Practice guidelines were developed following the Academy of Nutrition and Dietetics stepwise approach. The process consisted of six steps: 1 . Determine the scope of the guideline. 2 . Conduct a systematic review. 3. Draft the guideline recommendations using the Nutrition Care Process as a framework. 4. Finalise the guideline during a face-to face meeting. 5. Conduct internal and external review and revise accordingly. 6. Publish guideline.

\section{Results}

The process resulted in 25 recommendations for dietary counselling. Most recommendations are based on expert opinion only, due to the lack of studies in this field and showed similar levels of consensus between the expert group and external review by allergists. However, there were nine recommendations where the consensus differed.

\section{Conclusion}

This guideline provides a comprehensive guide to dietary counselling for food allergy by dietitians in Switzerland. It will inform best practice and improve patient-centred care and encourage a consistent approach, but it will need to be reviewed and updated as more robust evidence is produced.

\section{Keywords}

dietary counselling, food allergy, practice guidelines, children, dietitians

\author{
Abbreviations \\ CMA: Cow's milk allergy \\ NCP: Nutrition Care Process \\ NICE: The National Institute for Health and Care Excellence \\ PICO: Patient, Intervention, Comparison, Outcome
}




\section{Acknowledgements}

The authors would like to thank all allergists for taking part in the external review and for providing their opinions and comments. Furthermore, they would also like to thank Klazine van der Horst (Bern University of Applied Sciences) and Helena Jenzer (Bern University of Applied Sciences) for providing support by allowing internship students to work on this project. In addition, they would like to thank the Ulrich Müller-Gierok Stiftung for their financial support of the project. 


\section{Background}

An allergy is a hypersensitivity reaction initiated by immunologic mechanisms [1]; the World Allergy Organisation estimates the incidence of food allergy in toddlers at five to eight percent [2] and it appears to be increasing globally [3]. In this age group, staple foods including cow's milk, hen's egg, wheat, and foods that are difficult to avoid, such as peanuts and hazelnuts, often cause allergic reactions [4]. Food allergies are commonly managed by the avoidance of allergy-inducing substances [5]. However, long-term elimination diets without supervision can lead to nutrient deficiency, poor nutritional status [6] and a less varied diet [7]. Moreover, the elimination and replacement of problem foods can lead to increased strain on families and is associated with fear of accidental contamination, especially if multiple or difficult to avoid foods are involved [8]. All of these factors can result in a significantly lower quality of life for the person concerned and his/her family [9].

Patients with confirmed food allergy need clear recommendations and guidance from a qualified health professional to implement the elimination diet into daily life. European and international guidelines recommend involving dietitians with competencies in food allergy, including diagnosis and management [5, 10-12]. The roles that dietitians should fulfil in the management of children with food allergy differs between different guidelines and the description of tasks remains unclear. The European guideline and the German guideline list topics which should be covered in dietary counselling of patients with food allergy [5, 12] and the European Academy of Allergy and Clinical Immunology recently published competencies for healthcare professionals working in allergy [13]. The guideline by the Australasian Society of Clinical Immunology and Allergy is the only one that clearly defines the role of a dietitian in the diagnosis and management process and gives concrete recommendations for dietitians working with patients with food allergy [14]. Other professional societies including the Academy of Nutrition and Dietetics and the International Network for Diet and Nutrition in Allergy, have published position papers on the role of a dietitian in the diagnosis and management of patients with food allergy [15, 16]. However, these documents are mainly based on expert opinions and their development was not structured nor was their influence evaluated.

Guidelines provide a standardised approach to practice and are able to optimise patient care by providing consistency across healthcare settings $[17,18]$. They also improve the effectiveness of practice by reducing risk of harm and ineffective variations in care $[18,19]$. However, it is widely acknowledged that clinical guidelines should be adapted to meet individual needs and preferences where possible [20]

Therefore, the aim of this project was to develop a guideline for dietitians counselling children with diagnosed IgE-mediated food allergy. A special focus was placed on children with cow's milk allergy (CMA) as they are particularly affected by nutrient deficiencies [21, 22].

The guideline can be used by dietitians working in private practice and in hospitals in Switzerland. Moreover, this approach can be transferred to inform guideline development in other countries. The goals of this guideline are to improve patient quality of life, to avoid unnecessary food restrictions, to enable adequate nutrient intakes, to 
provide strategies on avoiding accidental allergen uptake, and to facilitate general allergen avoidance in the daily lives of children with IgE-mediated food allergy and their families.

\section{Methods}

This guideline is based on the stepwise approach for development of evidence-based nutrition practice guidelines by the Academy of Nutrition and Dietetics, with slight modification [23]. Table 1 outlines the implementation process. This method was chosen as it structures the guideline according to the Nutrition Care Process (NCP) which is a standardised framework for dietetic practice that is recommended to be used by the Swiss professional society of dietitians (SVDE). The NCP is composed of four steps of patient care; nutrition assessment, nutrition diagnosis, nutrition intervention, plus nutrition monitoring and evaluation [24].

Table 1 Implementation of guideline development process by the Academy of Nutrition and Dietetics for the practice guideline of children with IgE-mediated food allergy [23]

A guideline development group was convened and comprised JE, SB, CR and an expert group of health professionals, selected according to their knowledge, competency and expertise in food allergies. The experts included ten dietitians from all areas of the German speaking part of Switzerland working in the field of food allergy, as dietary counsellors for hospitals or in private practice. The expert group also included a representative of the national patient organisation aha! Swiss Allergy Centre and one paediatric allergist. The group undertook a stepwise approach to the development of the guideline.

Step 1: Scope of the guideline: This step involved developing a goal for the guideline and relevant practice questions formatted by the PICO structure (Patient, Intervention(s) or Exposure(s), Comparison and Outcome) [25]. The expert group evaluated these questions using a 5-point scale regarding their relevance for practice (0 not relevant to 5 very relevant) (Online Resource 1 ).

Step 2: Systematic review: In undertaking step 1, by screening guidelines, expert reviews and position papers, three topics were identified which were expected to be found in primary literature. These were 'formula for infants with CMA', 'dietary advice for patients with food allergy' and 'growth, nutrient intake and food allergy'. Systematic reviews were conducted on these three topics using the five-step approach recommended by the Academy of Nutrition and Dietetics [26]. CR and JE searched for articles in Medline ${ }^{\circledR}, \mathrm{Embase}^{\circledR}$ and Cochrane ${ }^{\circledR}$ and included relevant studies regarding predefined inclusion and exclusion criteria. Two authors (CR and JE) critically appraised these studies. CR and JE summarised the evidence (Online Resource 2) and wrote a conclusion statement (table 2). Those statements informed the recommendations to be included in this guideline.

Table 2 Summary of the systematic literature search using the method of the Academy of Nutrition and Dietetics [26] 
Step 3 Draft the guideline: Two authors drafted the guideline (SB and JE) using the NCP structure for guidance based on the results of the systematic reviews conducted in step 2, existing guidelines, position papers, expert reviews and a qualitative study based on interviews with Swiss dietitians [27] (Online Resource 3). The expert group commented on this draft using an online Sharepoint ${ }^{\circledR}$. Table 3 shows a summarised version of the Academy of Nutrition and Dietetics rating scheme and grading system. Evidence is based on the elements of quality, consistency, quantity, clinical impact and generalisability.

Table 3 The rating scheme for the strength of the recommendations adapted from the Academy of Nutrition and Dietetics [23]

Step 4 Face-to-face meeting: The agenda for the face-to-face meeting to finalise the guideline was based on the remaining draft comments. The guideline was adapted according to the results of the meeting.

Step 5 Review and revise the guideline: Internal Review: Two rounds of an online Delphi Survey were sent to the experts [28]. Recommendations receiving less than $70 \%$ full agreement in the second round were excluded from the guideline. An online questionnaire was sent to the experts of the guideline development group using Survey Monkey ${ }^{\circledR}$. For each recommendation respondents registered their agreement using a 5-point Likert scale (1 fully agree to 5 strongly disagree). Furthermore, they had the option to add comments. The Delphi process reduced recommendations from 31 to 25 . Additionally, these 25 recommendations were sent to allergists working in the German speaking part of Switzerland for external review. Sixteen paediatric allergists answered to what extent they agreed that dietitians should fulfil these tasks on a Likert scale ( 1 fully agree to 5 strongly disagree). Internal and external review were analysed using Excel ${ }^{\circledR}$. The frequency of the answers 'fully agree' and 'considerably agree' of the internal and external review is reported in tables 4 to 6.

\section{Ethics}

Participants of the expert group signed an informed consent form. The project was ethically approved by the Research Ethics Committee for the Faculty of Health \& Human Sciences and Peninsula Schools of Medicine \& Dentistry, Plymouth University. A jurisdictional inquiry was submitted to the Ethics Committee Bern, who advised that it did not require their approval, because no generalisable and health related data was obtained in this research project.

\section{Results}

The final version of the practice guideline consists of 25 practice recommendations. Nine recommendations for the nutrition assessment of children with diagnosed IgE-mediated food allergy (table 4). Thirteen recommendations for nutrition intervention (table 5) and three for nutrition monitoring (table 6). The recommendation to define nutrition diagnoses was excluded as a consequence of the Delphi rounds it did not reach the required consensus level, leaving recommendations for three of the NCP steps. 
There are only three recommendations that are based on published research evidence in addition to expert opinion. These are recommendation 10 on substitutes for children with CMA, recommendation 12c on supplementation for 'prevention and therapy of nutrition deficiencies' and recommendation 14e on 'when indicated discuss oral challenges with allergist' for quality of life promotion. All other recommendations are based on expert opinion of guidelines, position papers, expert reviews, interviews with dietitians and the opinion of the expert group.

The majority of the recommendations showed similar levels of consensus between the expert group and allergists. However, there were nine recommendations where the results differed by $20 \%$ or more; $9 c, 11 b, 11 c$, 11d, 11e, 15c, 17, 24 and 25 (tables 4-6).

Table 4 Evidence and consensus level for the recommendations relating to the nutrition assessment process

Table 5 Evidence and consensus level for the recommendations relating to the nutrition intervention process

Table 6 Evidence and consensus level for the recommendations relating to the nutrition monitoring and evaluation process

The full guideline with background information including the references on which the recommendation is based, and advantages and disadvantages of its implementation can be downloaded in German on the Bern University of Applied Sciences website https://www.bfh.ch/dam/jcr:34f97a5a-0065-45ba-8340-fc37e0f62abe/ERNA.pdf. An update of the guideline will be provided in five years.

\section{Discussion}

This project has produced a guideline to assist dietitians in counselling children with food allergies, based on all available evidence. It is focussed on the management of food allergy, as this is the usual role of dietitians in Switzerland, even though we would appreciate them being more involved in diagnosis. At present this largely remains the domain and responsibility of allergists in Switzerland. Consensus levels of the expert group and allergists were used in combination with the NCP to form the recommendations and provide a more targeted approach to the development of the guideline. The majority of the recommendations showed similar levels of consensus between the two groups. However, there were a small number of recommendations where the results differed, as outlined in table 4-6. This difference highlights the importance of interprofessional collaboration in the treatment and management of food allergy. With greater interprofessional working and more effective communication between different health professionals, such as dietitians and allergists, fewer discrepancies in opinion may occur resulting in more efficient patient care.

Recommendation $11 \mathrm{~b}$ states partially hydrolysed infant formula is not recommended as a breast milk substitute, but the experts' and allergists' did not agree with a difference in the consensus level of $28 \%$. While it is recognised 
a small number of infants may tolerate partially hydrolysed infant formula, expert guidelines on management of CMA do not recommend its use [21, 22, 29]. Similarly, there was a $20 \%$ difference in consensus levels on recommendation $11 \mathrm{c}$ and $11 \mathrm{~d}$; lactose free milk and milk drinks, and cereal or nut drinks, should not be recommended as a breastmilk substitute. Nut and cereal drinks are not nutritionally adequate, often low in energy, protein, and many vitamins and minerals, which is why they should not be recommended [21]. Lactose free formula is also not recommended due to the content of intact cow's milk protein which can cause an allergic reaction [21]. Recommendation 11e, with a 31\% discrepancy, concerns infant formula of other mammalian milks, which also potentially contain proteins which could cause an allergic reaction [21]. However, the DRACMA guidelines of the World Allergy Organisation from 2010 recommend milk of other mammalians for individual patients when diagnostic indicates that they are tolerated [11]. Moreover, recent research has found camel's milk to be safe and well tolerated in patients with CMA over one year of age [30]. Both may explain the difference in opinion. For a revision of the guideline, it may be beneficial to separate products that are unsuitable due to allergological concerns from those being nutritionally inadequate as breastmilk substitute. This may lead to a clearer distinction and prevention of any misunderstanding.

Considerable disagreement was also seen for recommendation $15 \mathrm{c}$ : Communicating information about handling precautionary labelling (Food law), where there was a $27 \%$ difference in consensus levels. It is obviously in the best interest of the patient to educate them on identification of the allergen, so it can be avoided [16]. Correct label identification has been shown to be associated with prior instruction by a dietitian [31]. According to a survey in the UK however, dietitians seem to be more cautious in recommending eating foods with precautionary labelling than allergists [32]. Even though legislation on precautionary labelling is slightly different in Switzerland, in the way that it is mandatory, if a certain amount of the allergenic ingredient is or may be exceeded, the questions remains who should avoid products labelled this way. A common agreement between allergist and dietitians regarding labelling and who would discuss this with the patient would be in the best interest of the patient to avoid confusion. This is especially necessary as questions on precautionary labelling are frequently raises in dietary counselling of patients with food allergies.

The evidence levels for most recommendations in this guideline are low with most being expert opinion. Food allergy is a broad topic involving a vast number of different foods and mechanisms and the literature can often be conflicting on what advice should be provided to patients. Limited studies are available on dietary advice for food allergy which is partly due to ethical issues with performing randomised controlled trials with allergic individuals [33]. Most studies focus on diagnosis of food allergy rather than management. Working collaboratively using a multidisciplinary approach to food allergy is important both in practice and in research settings to provide effective patient-centred care.

The guideline is structured according to the NCP resulting in a series of recommendations designed for clinical practice. However, some clinicians may find the length and detail of the guideline unacceptable, meaning the guideline is not implemented. It is also recognised that implementation of the guidelines by dietitians, to standardise care and patient management with the goal of improving care, may be difficult and challenging due 
to limited time resources and daily routine. As dietitians in Switzerland are used to working with the NCP and know its structure, it might be easier to extract the relevant information and use the full guideline as a lookup document. We will evaluate the implementation the guideline when we revise it and will shorten it, if necessary. Lastly, counselling strategies vary between different allergies, which make it difficult to define specific recommendations for each different allergy. For example, in children with CMA it is important to find alternative calcium sources, whereas in peanut allergic children nutrient deficiencies are not relevant. In these children it is more important to empower patients and their families to detect hidden peanut protein.

The next step is to evaluate the effectiveness of dietary counselling defined by this project. A cohort study is being undertaken in several hospitals across the German speaking part of Switzerland. Dietitians will be asked to document the process of using the guideline and this will be evaluated by asking patients about the impact of the counselling on their quality of life, frequency of allergic symptoms, growth and food diversity.

This newly developed guideline provides a clearer view of the role of a dietitian in supporting the patientfocussed management of food allergy. The recommendations will guide dietitians through the process of counselling and can be used as a tool to document progress with patients. It can be used by dietitians in private practice and in hospitals and is especially relevant for dietitians new to the field of food allergies. Furthermore, the discussions and written exchanges within the guideline development group offered the possibility to adopt a common understanding on dietary counselling of children with food allergy.

In conclusion, we have developed a comprehensive guideline, based on the best available evidence and expert opinion, to support dietary counselling for food allergy. It will help ensure consistency of care between experienced and less experienced specialist paediatric allergy dietitians to improve the quality of life of food allergic children and their families and reduce the burden of food exclusion.

\section{Funding}

This study was partially funded by 'Allergiestiftung Ulrich Müller-Gierok'. The foundation did not have any influence on the content of the guideline.

\section{Author contribution}

All authors contributed to the guideline development process. Literature search and analysis was done by Claudia Relats and Julia Eisenblaetter. The first draft of the guideline was written by Selina Bürklin and Julia Eisenblaetter. The first draft of the manuscript was written by Julia Eisenblätter and Ashley Gschwend. All authors commented on previous versions of the manuscript and read as well as approved the manuscript.

\section{Conflict of interest}

Mary Hickson has received a research grant from the General Education Trust of the British Dietetic Association and an honorarium for speaking at a symposium from Fresenius Kabi. Julia Eisenblaetter has received a research 
grant from the Swiss Federal Safety and Veterinary Office. The rest of the authors declare that they have no conflict of interests.

\section{References}

1. Johansson SG, Hourihane JO, Bousquet J, Bruijnzeel-Koomen C, Dreborg S, Haahtela T, et al. A revised nomenclature for allergy. An EAACl position statement from the EAACl nomenclature task force. Allergy. 2001;56:813-24.

2. Alessandro Fiocchi, Hugh A. Sampson, Sami L. Bahna. Food Allergy. In: Pawankar R, Holgate ST, Canonica GW, Lockey RF, Blaiss MS, editors. World Allergy Organisation (Hg.) - Food Allergy: Update 2013; 2013. p. 54-59.

3. Prescott SL, Pawankar R, Allen KJ, Campbell DE, Sinn JK, Fiocchi A, et al. A global survey of changing patterns of food allergy burden in children. World Allergy Organ J. 2013;6:21. doi:10.1186/1939-4551-621.

4. Ferrari GG, Eng PA. IgE-mediated food allergies in Swiss infants and children. Swiss Med Wkly. 2011;141:w13269. doi:10.4414/smw.2011.13269.

5. Worm M, Reese I, Ballmer-Weber B, Beyer K, Bischoff S, Classen M, et al. Guidelines on the management of IgE-mediated food allergies: Allergo Journal International. Allergo J Int. 2015;24:256-93. doi:10.1007/s40629-015-0074-0.

6. Flammarion S, Santos C, Guimber D, Jouannic L, Thumerelle C, Gottrand F, Deschildre A. Diet and nutritional status of children with food allergies. Pediatr Allergy Immunol. 2011;22:161-5. doi:10.1111/j.1399-3038.2010.01028.x.

7. Maslin K, Dean T, Arshad SH, Venter C. Dietary variety and food group consumption in children consuming a cows' milk exclusion diet. Pediatr Allergy Immunol. 2016;27:471-7. doi:10.1111/pai.12573.

8. Cummings AJ, Knibb RC, King RM, Lucas JS. The psychosocial impact of food allergy and food hypersensitivity in children, adolescents and their families: a review. Allergy. 2010;65:933-45. doi:10.1111/j.1398-9995.2010.02342.x.

9. Flokstra-de Blok, B M J, van der Velde, J L, Vlieg-Boerstra BJ, Oude Elberink, J N G, DunnGalvin A, Hourihane JO'B, et al. Health-related quality of life of food allergic patients measured with generic and disease-specific questionnaires. Allergy. 2010;65:1031-8. doi:10.1111/j.1398-9995.2009.02304.x.

10. NICE. Food allergy in children and young people: Diagnosis and assessment of foodallergy in children and young people in primary care and community settings. London; 2011.

11. Fiocchi A, Brozek J, Schunemann H, Bahna SL, Berg A von, Beyer K, et al. World Allergy Organization (WAO) Diagnosis and Rationale for Action against Cow's Milk Allergy (DRACMA) Guidelines. World Allergy Organ J. 2010;3:57-161. doi:10.1097/WOX.0b013e3181defeb9.

12. Muraro A, Werfel T, Hoffmann-Sommergruber K, Roberts G, Beyer K, Bindslev-Jensen C, et al. EAACI food allergy and anaphylaxis guidelines: diagnosis and management of food allergy. Allergy. 2014;69:1008-25. doi:10.1111/all.12429.

13. Skypala IJ, Jong NW de, Angier E, Gardner J, Kull I, Ryan D, et al. Promoting and achieving excellence in the delivery of Integrated Allergy Care: the European Academy of Allergy \& Clinical Immunology competencies for allied health professionals working in allergy. Clin Transl Allergy. 2018;8:31. doi:10.1186/s13601-0180218-7.

14. ASCIA. Food Allergy Clinical Update for Dietitians. 2017. https://www.allergy.org.au/images/stories/pospapers/ASCIA_HP_Clinical_Update_Food_Allergy_2017_di etitian_version.pdf. Accessed 6 Nov 2017.

15. Venter C, Laitinen K, Vlieg-Boerstra B. Nutritional aspects in diagnosis and management of food hypersensitivity-the dietitians role. J Allergy (Cairo). 2012;2012:269376. doi:10.1155/2012/269376.

16. Collins SC. Practice Paper of the Academy of Nutrition and Dietetics: Role of the Registered Dietitian Nutritionist in the Diagnosis and Management of Food Allergies. J Acad Nutr Diet. 2016;116:1621-31. doi:10.1016/j.jand.2016.07.018. 
17. Melnyk BM. Important Information About Clinical Practice Guidelines: Key Tools for Improving Quality of Care and Patient Outcomes. Pediatrics. 2012;130:e399-407. doi:10.1542/peds.2011-2087.

18. Hollon SD, Areán PA, Craske MG, Crawford KA, Kivlahan DR, Magnavita JJ, et al. Development of clinical practice guidelines. Annu Rev Clin Psychol. 2014;10:213-41. doi:10.1146/annurev-clinpsy-050212-185529.

19. Kredo T, Bernhardsson S, Machingaidze S, Young T, Louw Q, Ochodo E, Grimmer K. Guide to clinical practice guidelines: the current state of play. Int J Qual Health Care. 2016;28:122-8. doi:10.1093/intqhc/mzv115.

20. van Dulmen SA, Lukersmith S, Muxlow J, Santa Mina E, Nijhuis-van der Sanden MWG, van der Wees PJ. Supporting a person-centred approach in clinical guidelines. A position paper of the Allied Health Community - Guidelines International Network (G-I-N). Health Expect. 2015;18:1543-58. doi:10.1111/hex.12144.

21. Luyt D, Ball H, Makwana N, Green MR, Bravin K, Nasser SM, Clark AT. BSACl guideline for the diagnosis and management of cow's milk allergy. Clin. Exp. Allergy. 2014;44:642-72. doi:10.1111/cea.12302.

22. Lifschitz C, Szajewska H. Cow's milk allergy: evidence-based diagnosis and management for the practitioner. Eur. J. Pediatr. 2015;174:141-50. doi:10.1007/s00431-014-2422-3.

23. Papoutsakis C, Moloney L, Sinley RC, Acosta A, Handu D, Steiber AL. Academy of Nutrition and Dietetics Methodology for Developing Evidence-Based Nutrition Practice Guidelines. J Acad Nutr Diet. 2017;117:794-804. doi:10.1016/j.jand.2016.07.011.

24. Nutrition care process and model part I: the 2008 update. J Am Diet Assoc. 2008;108:1113-7. doi:10.1016/j.jada.2008.04.027.

25. Speckman RA, Friedly JL. Asking Structured, Answerable Clinical Questions Using the Population, Intervention/Comparator, Outcome (PICO) Framework. PM R 2019. doi:10.1002/pmrj.12116.

26. Handu D, Moloney L, Wolfram T, Ziegler P, Acosta A, Steiber A. Academy of Nutrition and Dietetics Methodology for Conducting Systematic Reviews for the Evidence Analysis Library. J Acad Nutr Diet. 2016;116:311-8. doi:10.1016/j.jand.2015.11.008.

27. Ruch L. Allergenfrei und bedarfsgerecht - Wie können Kinder mit Nahrungsmittelallergie(n) und deren Eltern bestmöglich beraten werden? [Bachelor Arbeit]. Bern: Berner Fachhochschule; 2017.

28. Keeney S, Hasson F, McKenna HP. The Delphi technique in nursing and health research. Chichester, West Sussex: Wiley-Blackwell; 2011.

29. Egan M, Lee T, Andrade J, Grishina G, Mishoe M, Gimenez G, et al. Partially hydrolyzed whey formula intolerance in cow's milk allergic patients. Pediatr Allergy Immunol. 2017;28:401-5. doi:10.1111/pai.12718.

30. Navarrete-Rodríguez EM, Ríos-Villalobos LA, Alcocer-Arreguín CR, Del-Rio-Navarro BE, Del Rio-Chivardi JM, Saucedo-Ramírez OJ, et al. Cross-over clinical trial for evaluating the safety of camel's milk intake in patients who are allergic to cow's milk protein. Allergol Immunopathol (Madr). 2018;46:149-54. doi:10.1016/j.aller.2017.06.005.

31. Joshi P, Mofidi S, Sicherer SH. Interpretation of commercial food ingredient labels by parents of foodallergic children. J. Allergy Clin. Immunol. 2002;109:1019-21. doi:10.1067/mai.2002.123305.

32. Turner PJ, Skypala IJ, Fox AT. Advice provided by health professionals regarding precautionary allergen labelling. Pediatr Allergy Immunol. 2014;25:290-2. doi:10.1111/pai.12178.

33. Silva D de, Geromi M, Panesar SS, Muraro A, Werfel T, Hoffmann-Sommergruber K, et al. Acute and longterm management of food allergy: systematic review. Allergy. 2014;69:159-67. doi:10.1111/all.12314. 